\title{
The effect of surface treatment of silica nanoparticles on the breakdown strength of mineral oil
}

\author{
Huifei Jin, Peter H.F. Morshuis, Johan J. Smit \\ Electrical Sustainable Energy \\ Delft University of Technology \\ Delft, the Netherlands \\ H.Jin@tudelft.nl
}

\begin{abstract}
In previous work, the results of AC breakdown tests showed that unmodified silica nanoparticles improve the breakdown strength of mineral oil based nanofluids, especially at a relatively high humidity level of around $25 \mathrm{ppm}$. It was proposed that, since the hydrophilic surface of unmodified silica nanoparticles can absorb water, this would lead to a reduction of free moisture in the bulk of the oil, which has a strong influence on the breakdown strength. In the present study this proposition is verified, by comparing the breakdown strength of two mineral oil based nanofluids: a reference with unmodified silica nanofluid and a nanofluid with Z-6011 modified silica. The silane coupling agent Z-6011 turns the surface of silica nanoparticles hydrophobic, thus preventing water adsorption.
\end{abstract}

Keywords-nanofluid; AC breakdown strength; mineral oil; silica; surface modification; humidity

\section{INTRODUCTION}

The concept "nanofluids" was introduced by Stephen Choi at Argonne national laboratory and refers to a two-phase mixture, containing a liquid phase, which is the host, and nanoparticles in suspension [1]. Nowadays, nanofluids are considered the next generation of heat transfer fluids. However, the electrical properties of nanofluids are still uncertain [2].

In previous work it was shown that nanofluids with untreated nanoscale silica have a higher AC breakdown strength than mineral oil at high moisture content [3]. The AC breakdown of mineral oil is very dependent on the moisture content, but to a lesser extent for silica nanofluids. The breakdown strength of both types of fluids increases with a decrease of the moisture content.

A hypothesis for the enhanced AC breakdown strength of silica nanofluids at higher humidity level was that the hydrophilic surface of silica nanoparticles can bind water, which leads to a lower moisture content of the oil itself, and thus to a higher breakdown strength. The focus of this study is on verifying this assumption by comparing the AC breakdown voltage of surface modified silica nanofluids and unmodified silica nanofluids.

\section{MATERIALS}

The unmodified silica nanoparticles were purchased from Sigma-Aldrich. The average particle size is $15 \mathrm{~nm}$, according to the datasheet. The surface modified silica nanoparticles were purchased from Nanoamor, USA. The average particle size is $25 \mathrm{~nm}$. The surfactant used is the silane coupling agent Z6011

\author{
Thomas Andritsch \\ Electronics and Computer Science \\ University of Southampton \\ Southampton, United Kingdom
}

by Dow Corning. Z6011 is a reactive chemical, containing an aminopropyl inorganic group according to the data sheet. Fig. 1 and Fig. 2 show the transmission electron microscopy (TEM) test results of unmodified silica and silica/Z6011 nanoparticles as received. It can be seen that the surface modified silica nanoparticles in Fig. 2 can be easier distinguished than the unmodified silica nanoparticles in Fig. 1. The silica/Z6011 nanoparticles have a spherical shape with a layer of surfactant on the edges. The shape of untreated silica nanoparticles is difficult to identify and the edges are not as clear. The surfactant helps to break the silica nanoparticle clusters.

The surface properties of the two types of silica nanoparticles were examined with thermal gravimetric analysis (TGA). TGA is a method of thermal analysis in which changes in physical and chemical properties of materials are analyzed as a function of increasing temperature, with the mass loss monitored. For the surface of silica nanoparticles, water is physical adsorbed below $190^{\circ} \mathrm{C}$. Hydroxyl groups bound through hydrogen bonds (vicinal silanols) are present on the silica surface up to $450^{\circ} \mathrm{C}$, while germinal silanols are present up to $800^{\circ} \mathrm{C}$, and free or isolated silanol groups up to a temperature of around $1000^{\circ} \mathrm{C}$ [4]. Fig. 3 shows the TGA results of unmodified silica in blue and for silica/Z6011 nanoparticles in red. From $40^{\circ} \mathrm{C}$ to $190^{\circ} \mathrm{C}$, unmodified silica nanoparticles are losing around $12.7 \%$ of their total weight, for silica/Z6011 the mass losses on the surface are $4.1 \%$. This indicates much more adsorbed moisture on the surface of pure silica nanoparticles than on surface modified silica nanoparticles. From 190 to $1000^{\circ} \mathrm{C}$, the mass loss is due to the combustion of hydroxyl groups. For unmodified silica and silica/Z6011 nanoparticles, the mass losses in this region are similar.

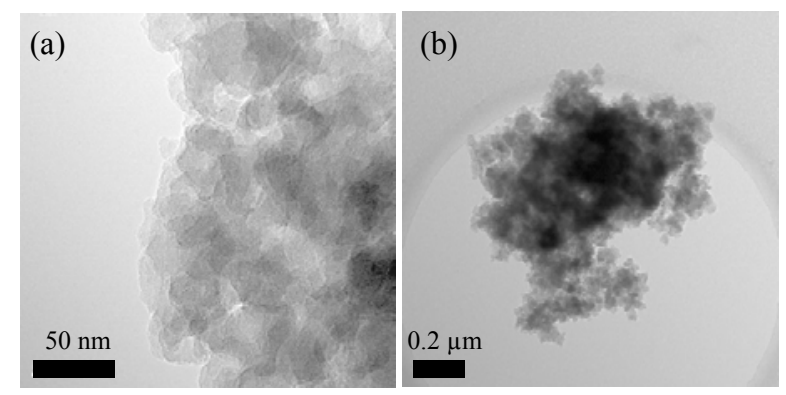

Fig. 1. TEM results of unmodified silica nanoparticles (a) 50 $\mathrm{nm}$ range; (b) $0.2 \mu \mathrm{m}$ range 

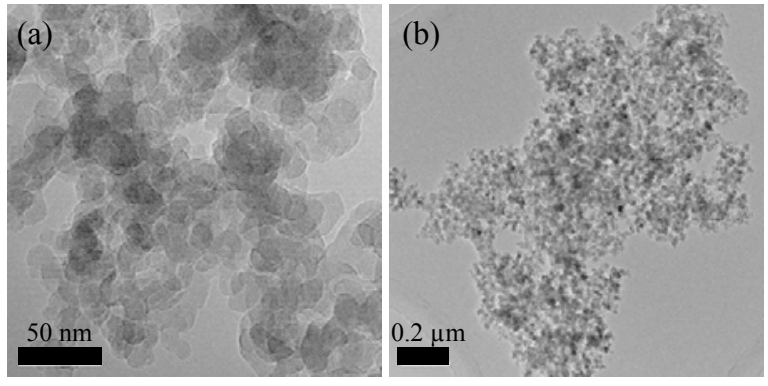

Fig. 2. TEM results of silica/Z6011 nanoparticles (a) $50 \mathrm{~nm}$ range; (b) $0.2 \mu \mathrm{m}$ range

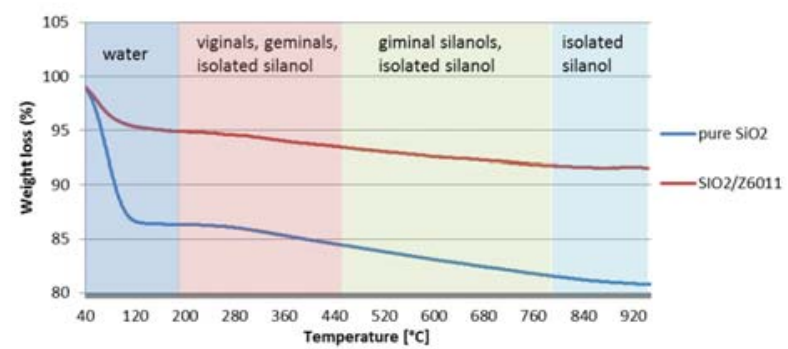

Fig. 3. TGA results of unmodified silica and silica/Z6011 nanoparticles

\section{AC BREAKDOWN STRENGTH}

\section{A. AC breakdown measurement results}

The AC breakdown voltage was measured with an OPG$100 \mathrm{~A}$ insulating oil tester according to the IEC60156 standard. The electrode configuration consisted of two spherical brass electrodes with $2.5 \mathrm{~mm}$ gap distance. The rate of voltage rise was $2 \mathrm{kV} / \mathrm{s}$. The silica nanofluids were prepared by means of ultrasonication. The mass fraction of the nanofluids is $0.01 \%$. For each fluid, 5 samples were prepared and for each sample, 12 measurements were performed. The samples were measured at two humidity levels: $25 \mathrm{ppm}$ and $15 \mathrm{ppm}$.

Fig. 4 shows the average AC breakdown voltage as well as the minimum and maximum value of mineral oil, $0.01 \%$ unmodified silica and silica/Z6011 nanofluids. Table I shows the average change in $\mathrm{AC}$ breakdown voltage compared to mineral oil for nanofluids.

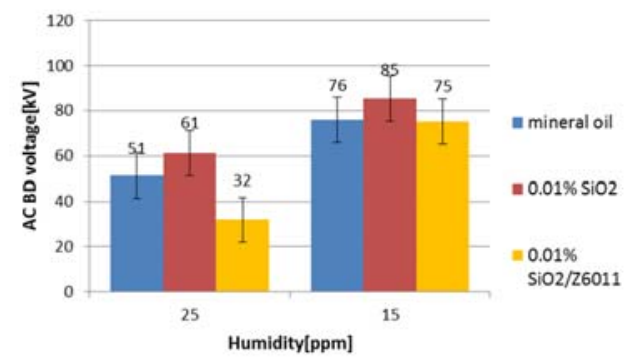

Fig. 4. AC breakdown voltage of mineral oil, $0.01 \%$ unmodified silica and silica/Z6011 nanofluids
TABLE I. AVERAGE AC BREAKDOWN VOLTAGE CHANGE IN NANOFLUIDS

\begin{tabular}{|c|c|c|}
\hline Humidity $\mid$ mass fraction & Unmodified silica NF & Silica/Z6011 NF \\
\hline $25 \mathrm{ppm}$ & $20 \%$ & $-37 \%$ \\
\hline $15 \mathrm{ppm}$ & $12 \%$ & $-1 \%$ \\
\hline
\end{tabular}

It can be seen that at $25 \mathrm{ppm}$ humidity, the AC breakdown voltage of silica/Z6011 nanofluids is about half the value of silica nanofluid without surfactant. $0.01 \%$ silica nanofluid without surfactant sees and increase in AC breakdown voltage compared to mineral oil by $20 \%$, while $0.01 \%$ silica/Z6011 nanofluid sees a decrease by $37 \%$ compared to mineral oil. At $15 \mathrm{ppm}$ humidity, the AC breakdown voltage of mineral oil and $0.01 \%$ silica/Z6011 is virtually identical. Unmodified silica nanofluid with $0.01 \%$ has a $12 \%$ higher average $\mathrm{AC}$ breakdown voltage than the other two sample types.

\section{B. Data analysis}

Due to the fact that transformers are designed according to the minimum withstand voltage level of the insulation rather than the average withstand voltage, Weibull statistical techniques are used to estimate the breakdown voltage obtained from AC breakdown data at lower failure probabilities [5]. For 2-parameter Weibull analysis, the breakdown probabilities are calculated according to:

$$
F(x)=1-\exp \left\{-(x / \eta)^{\beta}\right\}
$$

Where $F(x)$ is the cumulative probability of breakdown; $x$ is the AC breakdown voltage; $\beta$ is the shape parameter; $\eta$ is the scale parameter. Besides the parameters shown in equation (1), there is a correlation coefficient $\rho$, which is a measure of how well the linear regression model fits the data.

For a 3-parameter Weibull plot, the breakdown probabilities are calculated by:

$$
\left.F(x)=1-\exp \{-[(x-\gamma) / \eta)]^{\beta}\right\}
$$

Where $\gamma$ is the location parameter, the other parameters are the same as in equation (1)

1) AC breakdown strength at $25 \mathrm{ppm}$

The data of AC breakdown voltage of mineral oil, unmodified silica and silica/Z6011 nanofluids at $25 \mathrm{ppm}$ moisture content is analyzed with 3-parameter Weibull analysis. This is adjusted by the correlation coefficient $\rho$. Fig. 5 shows the 3-parameter Weibull plot of the three fluids with 95 confidence bound. This figure only shows the location parameter unadjusted part plot for a clear view. The blue circles represent the AC breakdown voltage of mineral oil, the red triangles show that for unmodified silica nanofluid, the yellow squares represent that of silica/Z6011 nanofluid. It can be seen that after adding $0.01 \%$ unmodified silica nanoparticles, the breakdown strength of mineral oil increases. Table II shows the breakdown voltage at different failure probabilities. In contrast, silica/Z6011 nanofluid shows a decreased breakdown voltage compared with mineral oil. For the 3-parameter Weibull plot, the distribution assumes that no failure will take place under the value $\gamma, \gamma$ is adjusted as a 
location parameter in the plot. For mineral oil, the distribution shows that the AC breakdown voltage won't be lower than $18.8 \mathrm{kV}$. By adding $0.01 \%$ unmodified silica nanoparticles, the threshold voltage is doubled. The threshold AC breakdown voltage is reduced by half due to $0.01 \%$ silica/Z6011 nanoparticles.

Table II shows that unmodified silica nanoparticles can increase the AC breakdown voltage of mineral oil by $61 \%$ at $0.1 \%$ failure rate, where the silica/Z6011 nanoparticles decrease the AC breakdown voltage of mineral oil by $47 \%$.

1) $\mathrm{AC}$ breakdown voltage at $15 \mathrm{ppm}$

Fig. 6 shows the 2-parameter Weibull plot of mineral oil, $0.01 \%$ unmodified silica and silica/Z6011 nanofluids at $15 \mathrm{ppm}$ moisture content with $95 \%$ confidence bound. Table III shows the AC breakdown voltage at different breakdown probabilities.

At 15 ppm humidity level, unmodified silica nanoparticles show less of an effect on the breakdown voltage of mineral oil as they did at $25 \mathrm{ppm}$ moisture content. Unmodified silica nanofluids still show up to $58 \%$ enhancement of the breakdown voltage at $0.1 \%$ probability. The particle concentration has less effect on the breakdown voltage of nanofluids than humidity. The silica/Z6011 has almost the same AC breakdown voltage as that of mineral oil.

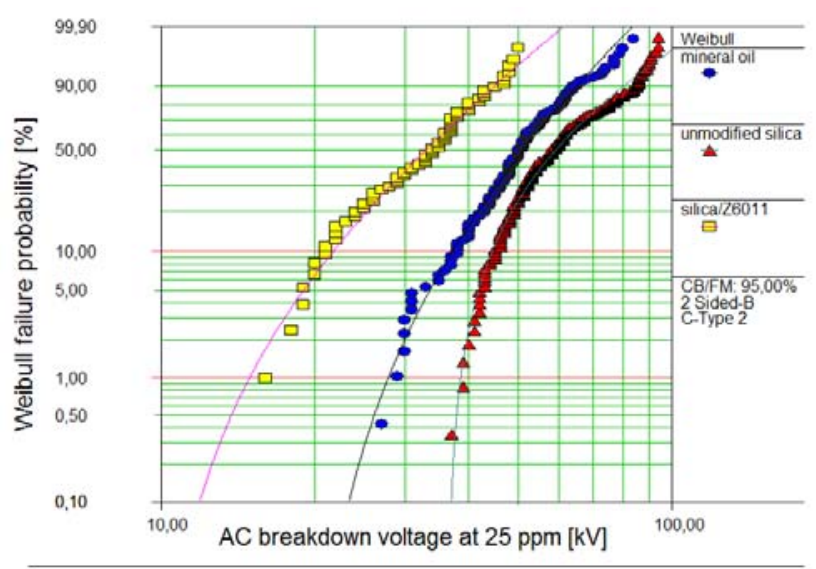

$\beta 1=3,32, \eta 1=36,21, \gamma 1=18,80, \rho=0,99$

Fig. 5. 3-parameter Weibull distribution of the AC breakdown voltage of mineral oil, unmodifed silica and silica/Z6011 nanofluids at $25 \mathrm{ppm}$ moisutre content

TABLE II. AC BREAKDOWN VOLTAGE OF MINERAL OIL, UNMODIFIED SILICA AND SILICA/Z6011 NANOFLUIDS AT 25 PPM MOISTURE CONTENT AT DIFFERENT PROBABILITIES

\begin{tabular}{|c|c|c|c|c|c|}
\hline \multirow{2}{*}{$\begin{array}{c}\text { BD } \\
\text { probabilities } \\
{[\%]}\end{array}$} & $\begin{array}{c}\text { Mineral } \\
\text { oil }\end{array}$ & \multicolumn{2}{|c|}{ Unmodified silica } & \multicolumn{2}{|c|}{ Silica/Z6011 } \\
\cline { 2 - 6 } & $\boldsymbol{B D}[\mathbf{k V}]$ & $\begin{array}{c}\boldsymbol{B D} \\
{[\mathbf{k V}]}\end{array}$ & enhancement & $\begin{array}{c}\boldsymbol{B D} \\
{[\mathbf{k V}]}\end{array}$ & enhancement \\
\hline 0.1 & 23 & 37 & $61 \%$ & 12 & $-47 \%$ \\
\hline 1 & 28 & 39 & $39 \%$ & 15 & $-53 \%$ \\
\hline 5 & 34 & 42 & $24 \%$ & 19 & $-44 \%$ \\
\hline 63.2 & 55 & 64 & $16 \%$ & 36 & $-34 \%$ \\
\hline
\end{tabular}

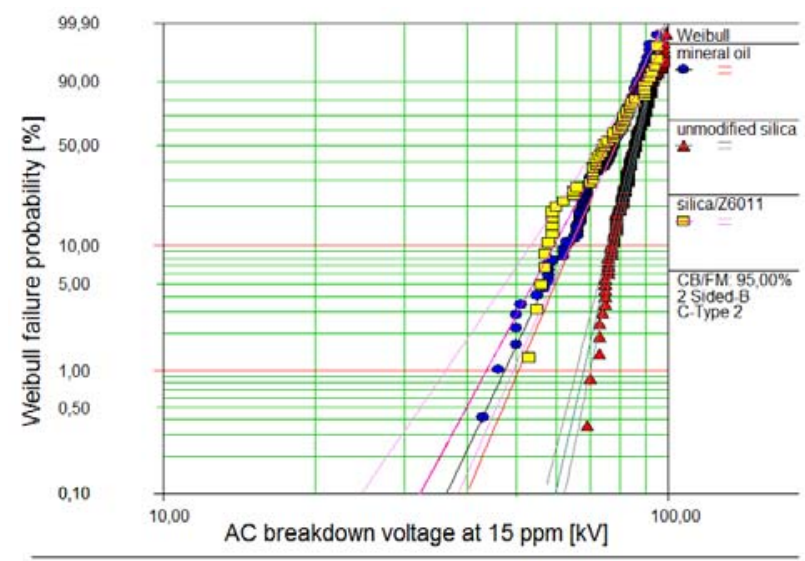

$\beta 1=8,72, \eta 1=80,34, \rho=0,99$
$\beta 2=17.89, \eta 2=88,02, \rho=0,98$

$\beta 2=17,89, \eta 2=88,02, \rho=0.98$
$B 3=7,63, \eta 3=79,77, \rho=0.97$

Fig. 6. 2-parameter Weibull distribution of the AC breakdown voltage of mineral oil, unmodifed silica and silica/Z6011 nanofluids at $15 \mathrm{ppm}$ moisutre content

TABLE III. AC BREAKDOWN VOLTAGE OF MINERAL OIL, UNMODIFIED SILICA AND SILICA/Z6011 NANOFLUIDS AT 15 PPM MOISTURE CONTENT AT DIFFERENT PROBABILITIES

\begin{tabular}{|c|c|c|c|c|c|}
\hline $\begin{array}{c}\text { BD } \\
\text { Probabilities } \\
{[\%]}\end{array}$ & $\begin{array}{c}\text { Mineral } \\
\text { oil }\end{array}$ & \multicolumn{2}{|c|}{ Pure silica } & \multicolumn{2}{c|}{ Silica/Z6011 } \\
\cline { 2 - 6 } & $\boldsymbol{B D}[\mathbf{k V}]$ & $\begin{array}{c}B \boldsymbol{B D} \\
{[\mathbf{k V}]}\end{array}$ & enhancement & $\begin{array}{c}\text { BD } \\
{[\mathbf{k V}]}\end{array}$ & enhancement \\
\hline 0.1 & 36 & 58 & $58 \%$ & 32 & $-11 \%$ \\
\hline 1 & 47 & 66 & $40 \%$ & 44 & $-6 \%$ \\
\hline 5 & 57 & 73 & $29 \%$ & 54 & $-5 \%$ \\
\hline 63.2 & 80 & 88 & $10 \%$ & 79 & $-1 \%$ \\
\hline
\end{tabular}

\section{DISCUSSION}

The moisture content has a big influence on the $\mathrm{AC}$ breakdown voltage of mineral oil and silica nanofluids. The breakdown voltage of both mineral oil and silica nanofluids increases with a decrease of moisture content. Untreated silica nanoparticles have a hydrophilic surface, which can bind the water in the oil onto their surface.

According to the TGA tests, the water adsorbed on the surface of the unmodified silica nanoparticles takes around $11 \%$ of the total weight of the silica nanoparticles. The unit ppm represents parts per million in mass. The total mass of one silica nanofluid sample is $400 \mathrm{~g}$. For $0.01 \%$ fill grade, the silica particle mass is around $0.04 \mathrm{~g}$. Hence the weight of water adsorbed on the surface of unmodified silica nanoparticles is around $0.0044 \mathrm{~g}$. The silica nanofluid has more remarkable influence on the AC breakdown behavior of mineral oil when the humidity is $25 \mathrm{ppm}$. At $25 \mathrm{ppm}$ humidity, the water mass in the $400 \mathrm{~g}$ nanofluid is $0.01 \mathrm{~g}$. Hence, around $44 \%$ of the water in the silica nanofluid can be adsorbed on the surface of the silica nanoparticles. Bound water on the surface of nanoscale silica has less effect on the dielectric breakdown strength of the mineral oil than unbound water [6]. The silica nanoparticles thus may lead to a reduced effect of moisture content on the breakdown behavior as long as the filler content is low enough to prevent percolation. 


\section{CONCLUSION}

In this study, the AC breakdown voltage of mineral oil, $0.01 \%$ unmodified silica and silica/Z6011 nanofluid is compared. The goal is to verify the assumption that silica nanoparticles increase the AC breakdown strength of mineral oil due to the fact that their hydrophilic surface can bind the water in mineral oil. The test results are:

- At 25 ppm moisture content, $0.01 \%$ unmodified silica nanofluid shows a $20 \%$ higher average $\mathrm{AC}$ breakdown voltage than mineral oil. While $0.01 \%$ silica/Z6011 nanofluid has a decreased AC breakdown voltage compared to mineral oil. At $0.1 \%$ failure rate, the change of $\mathrm{AC}$ breakdown strength of mineral oil due to $0.01 \%$ unmodified silica nanoparticles is $61 \%$ higher, while silica/Z6011 nanoparticles result in a $47 \%$ decrease.

- At $15 \mathrm{ppm}$ moisture content, the $\mathrm{AC}$ breakdown voltage of $0.01 \%$ silica/Z6011 nanofluid is almost the same as that of mineral oil, which is lower than that of unmodified silica nanofluid. The influence of silica nanoparticles on the breakdown strength of mineral oil at $15 \mathrm{ppm}$ is less than that at $25 \mathrm{ppm}$. At $0.1 \%$ failure rate, the change of $\mathrm{AC}$ breakdown strength of mineral oil is still 58\% increased by introducing $0.01 \%$ unmodified silica nanoparticles, while we observe an $11 \%$ decrease when introducing nanosilica modified with Z6011.
The test results show that the hydrophilic silica nanoparticles have a positive effect on the AC breakdown strength of mineral oil. On the other hand, the hydrophobic silica/Z6011 reduces the AC breakdown voltage of the nanofluid. Since the surface modification is the key difference of the samples investigated, the hydrophilic surface is most likely the reason for the changes in AC breakdown strength of the silica nanofluids. Although, the negative effect of silica modified with Z6011 on the AC breakdown strength of mineral oil still needs to be investigated.

\section{REFERENCES}

[1] S.K. Das, S.U.S. Choi, W. Yu, and T. Pradeep, Nanofluids: Science and Technology, Wiley-Interscience, 2008.

[2] J.G. Hwang, F. O'Sullivan, M. Zahn, O. Hjorstam, L.A.A. Petterson and R. Liu. "Electron scanvenging by conductive nanoparticles in oil insulated power transformer", Electrostatics Joint Conference Proceedings, pp. 1-12, 2009

[3] H. Jin, T. Andritsch, P. H. F. Morshuis and J. J. Smit, "AC breakdown voltage and Viscosity of Mineral Oil based $\mathrm{SiO}_{2}$ nanofluids", Conference on Electrical Insulation and Dielectric Phenomena, pp. 902 905, 2012.

[4] A. Rimola, D. Coasta, M. Sodupe, J. H. Lambert and P. Ugliengo, "Silica Surface Features and Their Role in the Adsorption of Biomolecules: Computatuinal Modeling and Experiments", Chemical reviews, pp. 4215-4313, 2013

[5] R. B. Abernethy, The New Weibull Handbook Fifth Edition, Reliability and Statistical Analysis for Predicting Life, Safety, Supportability, Risk, Cost and Warranty Claims, Abernethy, North Palm Beach, 2006.

[6] S. V. Kulkami, S. A. Khaparde, Transformer Engineering: Design and Practice, Technology \& Engineering, 2004 